\title{
8 Paul on the human vocation: Concluding summary
}

In this final chapter we briefly summarise our main results.

In chapter 1, we proposed that the problem of why Paul uses the language of 入oyıkós in Romans 12.1 deserves fresh consideration in its ancient context. We have sketched our own solution in outline: by using the language of $\lambda$ оуєкท $\lambda \alpha$ $\tau \rho \varepsilon i \alpha$, Paul appeals to the philosophical idea of a genuinely human vocation in the cosmos and claims its possible fulfilment in the communities of Christ-followers. Our solution rests on a fresh reading of some of the parallels that interpreters have adduced, in particular Epictetus 1.16.20 - 21, and on a broader con-

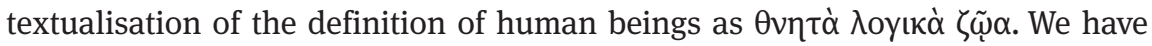
pointed out weaknesses and strengths of previous proposed solutions, which chiefly render גoyıкós either as "reasonable", "spiritual", or "genuine", though we have also discussed Reichert's proposal (“communicative”) and Scott's recent suggestion ("guided by reasoning thought”). These proposals either focus on linguistic parallels (the "semantic approach") or on thematic parallels (the "traditionsgeschichtlich approach"). The problem with the "semantic approach" is that the parallels are linguistically similar, but may be thematically different from Rom 12.1; conversely, the "traditionsgeschichtlich approach" finds parallels which are thematically similar (resting on a judgment about the topic), yet may be linguistically distant. We have advocated an approach which focuses on fewer qualitative parallels, which are explored in depth and within a broader ancient discourse. Finally, we have introduced some of our interpretative terms ("human vocation", "genuine humanness", "sign production").

In chapter 2, we have evaluated Scott's recent study on the semantics of $\lambda$ oylкóc, which identifies seven different categories of its use. We have found that Scott's study puts some important linguistic constraints on other solutions, but that it contains several methodological problems, and that his own proposal for Rom 12.1 contextualises too narrowly and misses the significance, within the

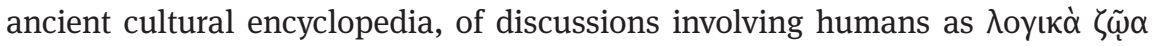
and of the evaluative connotations of such language within ancient discourse on what it means to be human. In particular, we have examined the evidence on which Scott's own proposal for Rom 12.1 rests and shown that it offers inadequate parallels for $\lambda$ оуıк่ $\lambda \alpha \tau \rho \varepsilon i \alpha$. In the same chapter (section 2.2), we have

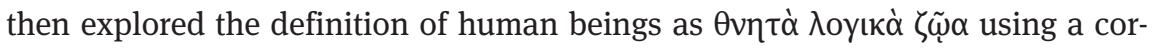
pus-based discourse analysis. We have shown in detail that this definition was pre-Pauline, associated mainly with Stoicism, but also became part of other philosophical traditions, and would have been well known to wider audiences. We

Ә OpenAccess. () 2021 Simon Dürr, published by De Gruyter. (cc) BY-NC-ND This work is licensed under the Creative Commons Attribution-NonCommercial-NoDerivatives 4.0 International License.

https://doi.org/10.1515/9783110750560-009 
thus show that it is plausible to assume that Paul could allude to the concept. We have then surveyed key discourses in which the notion of human beings as rational animals is used in discourse on the human place in the cosmos, on the human vocation, and on the ideals of genuine human life. This represents the first step in our approach towards a broader contextualisation of Rom 12.1.

In chapter 3, in complementary fashion, we have surveyed key texts in the wider Greco-Roman discourse on what it means to be human (mainly based on an evaluation of texts discussed in secondary literature). Through this broader contextualisation we have shown the prominent role given to the human endowment with reason in ancient anthropological reflection. These traditions link up with our investigation into the initially mainly Stoic definition of human be-

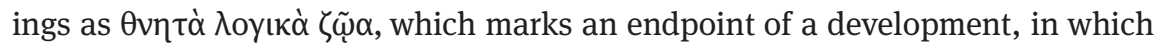
central aspects of what it means to be human are associated with humans' specific capacity as beings endowed with reason. This includes justice, worship, community life, and cultural production. Through this we could show that within the ancient encyclopedia, speaking about humans as rational animals is no mere classificatory exercise, but can be a way of speaking about genuine humanness. In the same chapter, we have also discussed the idea of a human role in the cosmos and the language used to express such an idea. In conversation with a study by Heinemann, we have identified three criteria for the notion of a human vocation in Greco-Roman philosophical contexts: divine intentionality, a task for human beings, and a distinct capacity on which this task is based, which can be recognised by human beings. We have then discussed this notion by means of several examples: we have analysed in detail an important passage in Iamblichus' Protrepticus (which uses Aristotle's lost work as a source) which shows the language and teleological motifs that form part of discussions of the human role in the cosmos; we examined further evidence in Seneca, which shows how normative conceptions of the human task are based upon their distinct capacity of being rational; finally, we have cited further examples which show that this idea was widespread and how it could be expressed using a variety of language.

In chapter 4, we have examined key texts in Epictetus which are necessary for understanding Epictetus 1.16.20 - 21 as a qualitative parallel to Romans 12.1. The main result is that we have shown that Epictetus 1.16 uses the language of $\lambda$ 入уıкós to speak about the distinct capacity on which a human vocation is based. Epictetus 1.16.20 describes what this vocation consists in with the image of singing hymns to God and uses the language of हैpyov (Epictetus

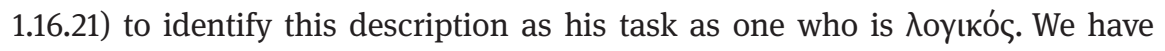
shown this through a detailed exegesis of the entire Discourse 1.16. We were able firmly to locate Epictetus on the map of the ancient discourse on being human by pointing out several resonances with themes and motifs we studied 
in chapters 2 and 3. Such an attempt can make plausible, as we argued, the proposal that Epictetus is an important parallel for Rom 12.1 because he brings to clearest expressions traditions which were widespread. We have further shown, based on Epictetus 1.6 and 1.16, that there is a two-part structure to the human vocation in Epictetus. We have analysed this structure as a sign production based on an understanding of the world in relation to God: humans are meant to use their specific capacity, reason, to discern God's providence and to produce signs of their understanding. Such "sign production” involves intelligent articulations of God's providential concern for human beings as well as an appropriately "ethical" response in terms of gratitude. The language of singing a "hymn to God" (Epictetus 1.16.20) is suitable as a description of the human vocation which captures both aspects. In this chapter we have also shown, based on an analysis of Epictetus 2.9, that the definition of human beings can be directly employed to speak about genuine humanness. All of this has prepared us for reading the reason language in Rom 12.1 in a vocational sense.

In the light of these findings, we have turned to Romans in chapters 5-7. In chapter 5, we have argued that there is strong evidence in Rom 1-8 for reading Paul's argument as being about genuine humanness as well as being about salvation, in a way in which both are fully integrated. We have shown this, first, by arguing that Rom 5.12-21 is key to the argument of Rom 1-8 and that it claims that the Christ event implies that a new way of being human is available for those in Christ. This was supported both by general considerations about the Adam-Christ comparison and in particular by our reading of the language of "ruling" in Rom 5.17 and 5.21. Second, we have confirmed the importance of genuine humanness for Romans $1-8$ by an analysis of Rom 1.18-32 which shows that Paul here describes the corruption of genuine humanness and that his critique of humans implies the idea of a human vocation. We have shown this both with reference to Jewish-scriptural traditions and with reference to Greco-Roman traditions. The broad contextualisation in terms of the wider discourse we have examined in chapter 3-4, both in terms of language and motifs, has allowed us to detect in Rom 1.18-21 not only the idea of a human vocation, but also a structure of the human vocation which is similar to the structure of the human vocation in Epictetus, namely an appropriate sign production based upon a true understanding of the world in relation to God. We have further argued that the strong emphasis upon the corruption of thinking in Rom 1.21-22 and Rom 1.28 supports our claim that the issue is genuine humanness. This is because, in the light of the wider discourse we studied in the previous chapters, the corruption of thinking is at the same time the corruption of that which makes humans human and is the basis of their human calling. Further support for our reading has come from Paul's use of Jewish traditions about dehumanising 
idolatry in Rom 1.23-25. That genuine humanness and the idea of a human vocation underlies Paul's argument in Rom 1.18-32 is particularly important in view of the strong links between Rom 1.18-32 and Rom 12.1-2. In this chapter, we have also argued, third, that Rom 6.1-11 claims that through the messiah's death and resurrection the bodily conditions for human beings have changed, such that it is now possible for those in Christ to exercise their genuinely

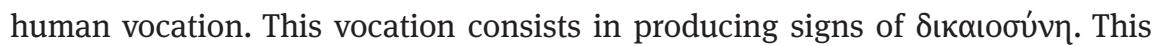
reading is confirmed in Rom 6.12-23, where we have argued that Paul's language of $\pi \alpha \rho i ́ \sigma \tau \alpha v \alpha$ describes the vocation of Christ-followers as a sign production which is missional in that it witnesses to and embodies the meaning of Christ's

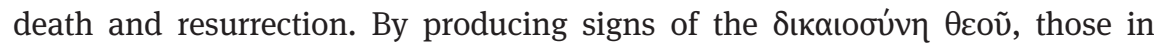
Christ make manifest the truth about how God has rescued human beings so that they can exercise their genuinely human role in the cosmos. This interpre-

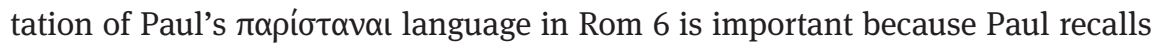
it in Rom 12.1b. Fourth, we have briefly argued that Rom 8.5-6 further supports our reading by emphasising the role of the Spirit for the renewed thinking required for the genuinely human vocation, while Rom 8.17-30 puts the human vocation into a dynamic relation to a cosmos in which the new creation has been inaugurated: human beings are called, in suffering and prayer, and in the power of the Spirit, to be people in whom the signs of new creation are already coming to birth. In these respects, Paul goes significantly beyond Epictetus and the philosophical tradition. Finally, we indicated how such an emphasis on genuine humanness makes excellent sense in terms of Paul's own sense of vocation as an "apostle to the Gentiles" (Rom 11.13). Having established these points we could then turn to Rom 12.1.

In chapter 6, we have proposed our novel explanation of Paul's reason language in Rom 12.1 and shown how it works exegetically in Rom 12.1-2. Key to our

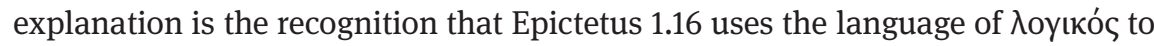
speak about the capacity upon which a human vocation is based, and that Epictetus 1.16 .20 - 21 is a parallel to Rom 12.1 in precisely this respect. We have demonstrated, first, that the syntax puts constraints upon any interpretation of the

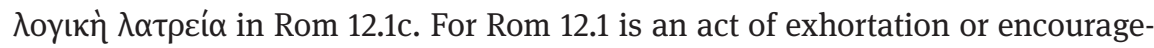
ment to a certain action (as marked by the $\pi \alpha \rho \alpha \kappa \alpha \lambda \varepsilon \tilde{\tau} v$ in Rom 12.1a; cf. Epictetus 1.16.21). This action is described as a "presentation of one's body as a living sac-

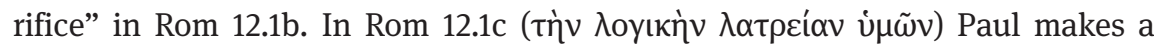
comment upon this action, using the reason language we set out to explain. This comment must contribute to the overall aim of exhortation to the action described in Rom 12.1. We have argued that the action described in Rom 12.1b is missional sign production for the new creation inaugurated in the messiah. This interpretation is strongly supported by the links created by Paul's use of 


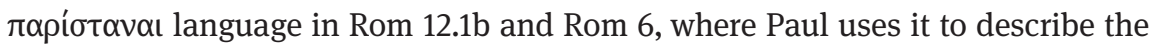
calling of those in Christ as a new service in which the body is used for produc-

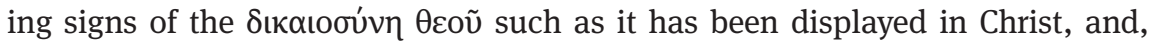
hence, the vocation of producing signs of new creation and the good news. In this interpretation, Paul's description, in Rom 12.1b, of the missional task of those in Christ as a sign production based upon an understanding of God as he has made himself known in Christ should be compared with Epictetus' description of the task of human beings as "singing hymns to God" (Epictetus 1.16.20). As we have seen, this is an apt image to express the two-part structure of the human vocation as an understanding of divine providence in the world and responding to it in appropriate sign production. Epictetus identifies this description as his vocation (हैрyov) as a human being (入оүıкós [Epictetus 1.16.21]). In our interpretation of Paul's reason language in Rom 12.1, Paul makes the same move: Rom 12.1c identifies the description of the missional sign production (Rom 12.1b) as the genuinely human vocation ( meets our syntactical criterion because arguing that a certain action is the fulfilment of one's role as a human being in the cosmos is an effective protreptic strat-

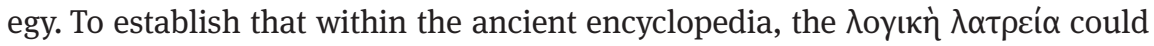
refer to a "genuinely human vocation" we needed to argue three points. First, that $\lambda \alpha \tau \rho \varepsilon i ́ \alpha$ could be used in Rom 12.1c to speak of a service to God as a vocation. We have made this plausible based on an investigation of Paul's own use of $\lambda \alpha \tau \rho \varepsilon i ́ \alpha$ and $\lambda \alpha \tau \rho \varepsilon u ́ \varepsilon ı v$ (including consideration of LXX tradition), an example

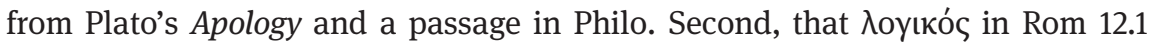
could refer to the specifically human capacity on which a vocation is based. Such a sense is clearly documented in our reading of Epictetus 1.16-20. Given that Epictetus 1.16.20-21 is a strong thematic parallel to Rom 12.1, and in the light of our overall considerations of the philosophical and wider cultural traditions we have treated in chapters 2-4, and whose significance for Rom 1-8 we established in chapter 5 , this assumption can claim strong support. Third, that

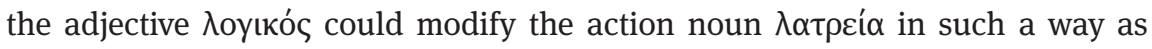
to point to its subject. We have shown that this is possible based on a general consideration of the ways in which adjectives can modify nouns, which includes the subject of such an action. We have confirmed this by looking at examples of adjectives modifying the noun $\lambda \alpha \tau \rho \varepsilon i ́ \alpha$. But we have demonstrated the point by discussing an example in Diogenes Laertius where the adjective Noyıkó is actually used to modify an action noun in such a way as to point to human beings

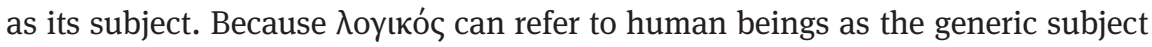
of a human task, and because $\lambda \alpha \tau \rho \varepsilon i ́ \alpha$ can refer to a service to God by any sub-

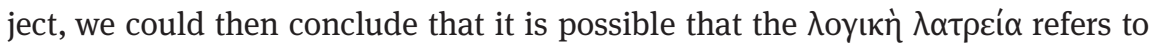
the idea of a human vocation. Owing to the aspirational dialectic inherent in the 
concept of a vocation we have argued that the best rendering of $\lambda$ "genuinely human vocation." The result of our new explanation of Paul's reason language in Rom 12.1 is that Paul presents the missional sign production in Rom $12.1 \mathrm{~b}$ as the genuinely human vocation in Rom 12.1c. We have then further shown in this chapter how Rom 12.2 coheres with our reading of Rom 12.1. We have argued that the renewal of the mind refers to an active process of appropriating the new understanding of God (in relation to the world) that has become available in

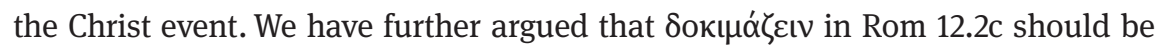
understood as vocational discernment. It is concerned with finding the best way, in a given situation, to use one's actions to produce signs of the good news and of the new creation inaugurated in the messiah.

In chapter 7, we have shown how our novel explanation of Paul's reason language emphasises a new aspect in how Rom 12.1-2 frames Rom 12-15. We have argued that Rom 12.1-2 implies that the missional sign production of those in Christ is their truly human vocation. This frames the actions to which Rom 12-15 exhorts as vocational signs. The notion of a human vocation (as a sign production based on an understanding of God) integrates what are traditionally called "theology" and "ethics". If Paul appeals to such a conception in Rom 12.1, as our new explanation of Paul's reason language suggests, then this would help explain the integration of Paul's "theology" and "ethics", which interpreters have claimed in various ways, by means of a concept that is part of the ancient encyclopedia. We have further shown that, in select passages in Rom 12.3-15.13, there are direct resonances with the main themes of our explanation of Rom 12.1-2 (genuine humanness, the human vocation, sign production, a new kind of thinking). We have established that Rom 12.3-8 emphasises vocational thinking with regards to the unity of the "body"; that, at several points in Rom 12.9 - 21 there is an emphasis on genuine humanness and a new kind of thinking; that Rom 13.11-14 amplifies the eschatological and christological dimensions of the truly human sign production; and, finally, that the argument of Rom 14.1-15.13 grounds an appeal for mutual welcome and unity in arguments about the Christ-followers' vocation and service to Christ. Towards the end of this passage, Paul makes it clear that in particular the unity of Jewish and Gentile Christ-followers, in their united worship and joint service, is the major sign of the new way of being genuinely human and the inaugurated new creation in Christ. Paul's own vocation is to exhort those in Christ to this way of fulfilling their role as human beings in a cosmos that is itself being transformed. 